06

\title{
Электрофизические и механические свойства композита с повышенной диэлектрической проницаемостью на основе сверхвысокомолекулярного полиэтилена, модифицированного углеродными нанотрубками
}

\author{
(С) И.А. Маркевич, ${ }^{1}$ Г.Е. Селютин, ${ }^{1}$ Н.А. Дрокин, ${ }^{2}$ А.Г. Селютин ${ }^{3}$ \\ ${ }^{1}$ Федеральный исследовательский центр „Красноярский научный центр СО РАН“ Институт химии и химической \\ технологии, \\ 660036 Красноярск, Россия \\ ${ }^{2}$ Федеральный исследовательский центр „Красноярский научный центр СО РАН“ Институт физики им. Л.В. Киренского, \\ 660036 Красноярск, Россия \\ ${ }^{3}$ Федеральный исследовательский центр „Институт катализа им. Г.К. Борескова СО РАН“, \\ 630090 Новосибирск, Россия \\ e-mail: 4ubekpam@mail.ru
}

Поступило в Редакцию 7 декабря 2019 г.

В окончательной редакции 7 декабря 2019 г.

Принято к публикации 22 января 2020 г.

Получен композит на основе сверхвысокомолекулярного полиэтилена (СВМПЭ) с добавкой 1 wt.\% многостенных углеродных нанотрубок (МУНТ) с повышенной диэлектрической проницаемостью $(\varepsilon=4.5)$, низкими диэлектрическими потерями $\left(\operatorname{tg} \delta=10^{-2}\right)$ в диапазоне частот от $100 \mathrm{~Hz}$ до $100 \mathrm{MHz}$, и изучены его основные механические характеристики. Материал имеет сниженную прочность при разрыве $22 \mathrm{MPa}$, высокое относительное удлинение до разрыва $700 \%$ и стойкость к истиранию на $37 \%$ выше, чем у чистого СВМПЭ. На основе результатов рентгенофазового анализа и дифференциальной сканирующей калориметрии показано, что изменения механических свойств композита обусловлены изменениями в структуре полимерной матрицы, происходящими вследствие воздействия высокоинтенсивного ультразвукового излучения, применяемого в процессе введения МУНТ в полимер.

Ключевые слова: сверхвысокомолекулярный полиэтилен, многостенные углеродные нанотрубки, композит.

DOI: 10.21883/JTF.2020.07.49450.391-19

\section{Введение}

В современной технике и технологии существует тенденция к переходу от традиционных материалов к полимерам и композитам на их основе, которые способны выдерживать экстремальные условия эксплуатации (низкие температуры, воздействие агрессивных сред, высокую влажность, деформационные нагрузки и т.д.). К таким материалам можно отнести сверхвысокомолекулярный полиэтилен (СВМПЭ), обладающий высокой износостойкостью, стойкостью к ударным нагрузкам и агрессивным средам, имеющий широкий температурный диапазон эксплуатации (от криогенных температур до $100^{\circ} \mathrm{C}$ ). Этот полимер широко применяется в различных областях техники и медицине [1-5]. Его мировое производство непрерывно растет, поэтому даже незначительное улучшение свойств материала неизбежно приведет к расширению сфер его использования. Повышение прочностных характеристик СВМПЭ является наиболее значимой задачей. При ее решении широко используется метод введения в полиэтилен различных наполнителей [6-8] (углеродные нанотрубки, графены, керамические частицы и др.), позволяющих в ряде случаев повысить предел прочности полимера более чем в 5 раз.
При введении абразивных частиц повышается стойкость к истиранию в 2-150 раз [9-11].

Одной из важных особенностей СВМПЭ является его радиопрозрачность в СВЧ диапазоне, так как он имеет диэлектрические потери порядка $10^{-4}$. В частности, перспективно использование СВМПЭ при создании радиопрозрачных укрытий, защищающих радиолокационную аппаратуру от климатических и внешних воздействий (ударов, агрессивных сред), а также в качестве материала подложек СВЧ фильтров или диэлектрических резонаторов. Для этого необходимо, чтобы полимер обладал повышенной диэлектрической проницаемостью (ДП) $\varepsilon>5$ и низкими диэлектрическими потерями $\operatorname{tg} \delta<10^{-3}$ в СВЧ диапазоне, а также высокими механическими характеристиками (прочность, износостойкость, ударная вязкость и пр.). Однако ДП чистого СВМПЭ составляет 2.3.

Одним из методов повышения ДП является введение в полимер высоких концентраций керамической фазы с большой ДП [12-14]. Однако это неизбежно приводит к ухудшению механических свойств материала и увеличению массы изделия $[15,16]$. Диэлектрическая проницаемость СВМПЭ может быть увеличена за счет введения электропроводящих углеродных нанотрубок (УНТ), 
как это сделано для других видов полимеров $[17,18]$. При этом удается сохранить диэлектрические потери на низком уровне порядка $10^{-3}$ [19]. С учетом теории поляризации по механизму Максвелла-Вагнера для наиболее эффективного увеличения ДП при сохранении низких диэлектрических потерь важно, чтобы УНТ были равномерно распределены в объеме полимерной матрицы в виде мельчайших субмикронных кластеров и индивидуальных наночастиц, изолированных друг от друга полимером.

Следует также отметить, что введение нанотрубок позволяет повысить прочностные свойства СВМПЭ [20-22]. По мнению авторов статьи [23], необходимым условием повышения прочностных свойств полимерного композита является не только высокое межфазное взаимодействие между матрицей и нанотрубками, но и равномерное распределение УНТ в объеме полимера. В противном случае кластеры УНТ будут являться концентраторами напряжений, ухудшающими свойства материала.

К настоящему времени композиты СВМПЭ-УНТ, обладающие высокой электропроводностью и повышенными прочностными характеристиками, исследованы достаточно подробно [20-22,24-33]. Однако работы, посвященные успешному получению и изучению СВМПЭ-УНТ композита, сочетающего высокие механические свойства, повышенную ДП и низкие диэлектрические потери, до сих пор не известны. Для изготовления такого материала необходимо выбрать способ синтеза, обеспечивающий однородное распределение УНТ в матрице СВМПЭ. Среди известных методик получения композитов на основе СВМПЭ с включениями наночастиц наиболее универсальным и эффективным является метод перемешивания компонентов в растворе. Данный способ синтеза позволяет получить композиты с различной однородностью распределения наполнителя [34] за счет гибкого регулирования условий проведения процесса (температуры, времени, жидкой среды, способа перемешивания, последовательности проведения операций и т.д.). Верный выбор концентрации наполнителя и режимов синтеза позволит обеспечить оптимальное распределение УНТ в полимерной матрице, при котором композит будет сочетать высокие механические свойства и необходимые величины электрофизических характеристик в СВЧ области.

Целью настоящей работы является синтез СВМПЭ композита, модифицированного многостенными углеродными нанотрубками (МУНТ), с повышенной ДП и низкими диэлектрическими потерями в широком диапазоне частот (от $100 \mathrm{~Hz}$ до $100 \mathrm{MHz}$ ) и изучение его основных механических характеристик. СВМПЭ композиты были получены методом перемешивания компонентов в растворе органического растворителя с использование ультразвукового воздействия высокой интенсивности.

\section{Эксперимент}

В настоящей работе использовали СВМПЭ компании Braskem (молекулярная масса $6.4 \cdot 10^{6} \mathrm{~g} / \mathrm{mol}$, средний размер частиц порошка $150 \mu \mathrm{m})$ и многостенные углеродные нанотрубки со средним диаметром $7 \mathrm{~nm}$, длиной $2-2.5 \mu \mathrm{m}$ и электропроводностью $2500 \mathrm{Sm} \cdot \mathrm{m}^{-1}$, синтезированные в Институте катализа им. Г.К. Борескова СО РАН (г. Новосибирск) [35].

Композиты на основе СВМПЭ с добавкой МУНТ были получены методом перемешивания компонентов в растворе органического растворителя с использование ультразвукового воздействия. На основе ранее проведенной работы [36] были подобраны оптимальные режимы синтеза материала, обеспечивающие наиболее однородное распределение наполнителя в полимерной матрице. Для получения композитов МУНТ обрабатывали в ксилоле ультразвуком (УЗ) интенсивностью не менее $100 \mathrm{~W} / \mathrm{cm}^{2}$ в течение $20 \mathrm{~min}$ до формирования однородной суспензии. Далее в суспензию МУНТ добавляли порошок СВМПЭ, и смесь обрабатывали УЗ интенсивностью не менее $100 \mathrm{~W} / \mathrm{cm}^{2}$ в течение $20 \mathrm{~min}$ при температуре $130^{\circ} \mathrm{C}$, в результате получали однородный раствор полимера и МУНТ в ксилоле. После фильтрования осадок высушивали в вакууме $48 \mathrm{~h}$ при температуре $90^{\circ} \mathrm{C}$. Концентрация МУНТ в композите составляла 1,4 и 8 wt.\%. После изучения электрофизических характеристик композитов среди них был выбран материал с повышенной диэлектрической проницаемостью и наиболее низкими диэлектрическими потерями, и исследованы его механические свойства (предел прочности, предел текучести, модуль упругости при растяжении, износостойкость).

Для определения влияния УЗ воздействия на механические свойства полимерного композита по описанной выше методике был синтезирован дополнительный образец СВМПЭ без МУНТ: порошок СВМПЭ в ксилоле подвергли УЗ обработке интенсивностью не менее $100 \mathrm{~W} / \mathrm{cm}^{2}$ в течение $20 \mathrm{~min}$ при температуре $130^{\circ} \mathrm{C}$, в результате чего получали однородный раствор полимера. После фильтрования осадок высушивали в вакууме $48 \mathrm{~h}$ при температуре $90^{\circ} \mathrm{C}$, полученный образце обозначили „СВМПЭ-УЗ““.

Экспериментальные образцы изготавливали горячим прессованием при давлении $6 \mathrm{MPa}$ и температуре $160^{\circ} \mathrm{C}$.

Изучение комплексной проводимости и комплексной относительной диэлектрической проницаемости композитов проводили в диапазоне частот от $100 \mathrm{~Hz}$ до $100 \mathrm{MHz}$ методом измерения импеданса с использованием векторного анализатора цепей E5061B (Agilent Technology). Сущность метода импедансной спектроскопии состоит в измерении переменного электрического тока, проходящего через исследуемые материалы, и определении дисперсии полного комплексного сопротивления (модуля импеданса $|Z|$ ) и фазы $\varphi$. Затем вычисляют действительную $Z^{\prime}(f)=|Z| \cdot \operatorname{Cos} \varphi$ и мнимую 
$Z^{\prime \prime}(f)=|Z| \cdot \operatorname{Sin} \varphi$ компоненты импеданса. Для проведения измерений импеданса $|Z|$ и фазы $\varphi$ к торцевым поверхностям образцов композитов прижимали тонкие электроды из индия с пренебрежимо малым переходным сопротивлением. Исследуемые образцы имели форму дисков диаметром $16 \mathrm{~mm}$ и толщиной $1 \mathrm{~mm}$.

Компоненты комплексной диэлектрической проницаемости и удельной проводимости вычисляли по следующим формулам [37]:

$$
\begin{aligned}
\varepsilon_{\mathrm{eff}}^{\prime}=\frac{-Z^{\prime \prime}}{\omega C_{0}\left(Z^{\prime 2}+Z^{\prime \prime 2}\right)}, \quad \varepsilon_{\mathrm{eff}}^{\prime \prime} & =\frac{-Z^{\prime}}{\omega C_{0}\left(Z^{\prime 2}+Z^{\prime 2}\right)}, \\
\sigma^{\prime}=Y^{\prime} \frac{d}{S}, & \sigma^{\prime \prime}=Y^{\prime \prime} \frac{d}{S},
\end{aligned}
$$

где $\omega-$ круговая частота, $C_{0}, d, S-$ геометрическая емкость, толщина и площадь пластин измерительной ячейки, $Y^{\prime}$ и $Y^{\prime \prime}$ - действительная и мнимая компоненты адмиттанса.

Измерение прочностных характеристик материала при растяжении (предел прочности, предел текучести, модуль упругости) осуществляли на установке Inspekt Table Blue $5 \mathrm{kN}$ фирмы Hegewald \& Peschke (Германия). Скорость растяжения составляла $500 \mathrm{~mm} / \mathrm{min}$. Исследуемые образцы имели форму полосок размером $60 \times 3 \times 2 \mathrm{~mm}$. Для каждого вида материала проводили не менее трех измерений, результаты усредняли.

Испытание композитов на стойкость к истиранию при скольжении по возобновляемой поверхности осуществляли на тестере MZ-4060 по ГОСТ 23509-79. В качестве абразива использовали наждачную бумагу зернистостью 160-200 $\mu \mathrm{m}$. Нормальная сила, прижимающая образец к барабану, составляла 10 N. Рассчитывали величину потери массы экспериментального образца по разности его массы до и после испытания на истираемость. Исследуемые на истирание образцы взвешивали с точностью $\pm 1 \mathrm{mg}$. Истираемость $(\Delta)$ композитов определяли по формуле

$$
\Delta=\frac{\left(m_{1}-m_{2}\right)}{m_{1}} 100 \%,
$$

где $m_{1}$ - потеря массы при истирании чистого СВМПЭ; $m_{2}$ - потеря массы при истирании композита. Величина $\Delta$ указывает, на сколько процентов уменьшилась потеря массы исследуемого материала при истирании по сравнению с исходным СВМПЭ. Для определения состояния истирающей способности наждачной бумаги через каждые пять испытаний проводили контрольное испытание образца чистого СВМПЭ. Если потеря массы уменьшалась более чем на $10 \%$, то наждачная бумага заменялась на новую. Исследуемые образцы были диаметром $16 \mathrm{~mm}$ и толщиной $6 \mathrm{~mm}$.

Поверхность образцов после испытания на истирание была исследована на сканирующем электронном микроскопе (СЭМ) Hitachi TM3000 Benchtop Scanning Electron Microscope (Япония).

Дифференциальную сканирующую калориметрию (ДСК) исследуемых образцов проводили на приборе
204 F1 Phoenix („Netzsch“, Германия) в соответствии с методикой ASTM D3418-15 в атмосфере аргона (скорость потока $30 \mathrm{ml} / \mathrm{min}$ ) в закрытых алюминиевых тиглях объемом $25 \mu 1$. Съемку образцов осуществляли по программе плавление-кристаллизация-плавление в температурном интервале от 25 до $160^{\circ} \mathrm{C}$ со скоростью $10^{\circ} \mathrm{C} / \mathrm{min}$. Температуру и энтальпию плавления определяли по данным второго плавления. Степень кристалличности $X$ полиэтилена рассчитывали по формуле

$$
X=\frac{\Delta H_{m}}{\Delta H_{0}} 100 \%
$$

где $\Delta H_{m}$ - энтальпия плавления образца, рассчитанная из площади под эндотермическим пиком плавления, $\Delta H_{m}=290 \mathrm{~J} / \mathrm{g}$ - энтальпия плавления полимера со степенью кристалличности 100\% [38].

В Сибирском центре синхротронного и терагерцового излучения (СЦСТИ) на станции № 2 „Прецизионная дифрактометрия и аномальное рассеяние“" методом рентгенофазового анализа (РФА) были проведены исследования структуры образцов материалов. Измерения проводили в геометрии Брэгга-Бертранно, с использованием слаборасходящегося рентгеновского пучка и кристалл-анализатора, что позволяло исключить уширения и смещения пиков, вызванные геометрией образцов. В связи с малым размером исследуемой области время экспозиции было выбрано $15 \mathrm{~s}$. Используемая длина волны рентгеновского излучения была $0.154 \mathrm{~nm}$, шаг сканирования $0.02^{\circ}$.

\section{Результаты и их обсуждение}

Прежде всего, в настоящей работе определили дисперсию импеданса исследуемых материалов и по формулам (1) рассчитали ДП в зависимости от частоты, для того чтобы выделить диэлектрический образец композита, который имеет высокую ДП и низкие диэлектрические потери.

На рис. 1 приведены частотные зависимости действительной компоненты комплексной ДП $\varepsilon^{\prime}$ и тангенса угла диэлектрических потерь $\operatorname{tg} \delta$ СВМПЭ композитов с различным содержанием МУНТ.

Видно, что с ростом концентрации МУНТ величины ДП и $\operatorname{tg} \delta$ увеличиваются (рис. 1). При этом чем выше концентрация наполнителя, тем ярче зависимость диэлектрических характеристик от частоты. Большие значения $\varepsilon^{\prime}$ и $\operatorname{tg} \delta$ композитов с содержанием МУНТ 4 и $8 \%$ объясняются поляризацией крупных электропроводящих кластеров МУНТ по механизму Максвелла-Вагнера. При этом в образце $8 \%$, имеющем удельную проводимость $1.5 \cdot 10^{2} \mathrm{Sm} \cdot \mathrm{m}^{-1}$, содержание МУНТ явно превышает перколяционную концентрацию, т.е. он имеет сквозные электропроводящие каналы нанотрубок. Этим объясняются огромные значение мнимой компоненты ДП и $\operatorname{tg} \delta$ на низких частотах. 

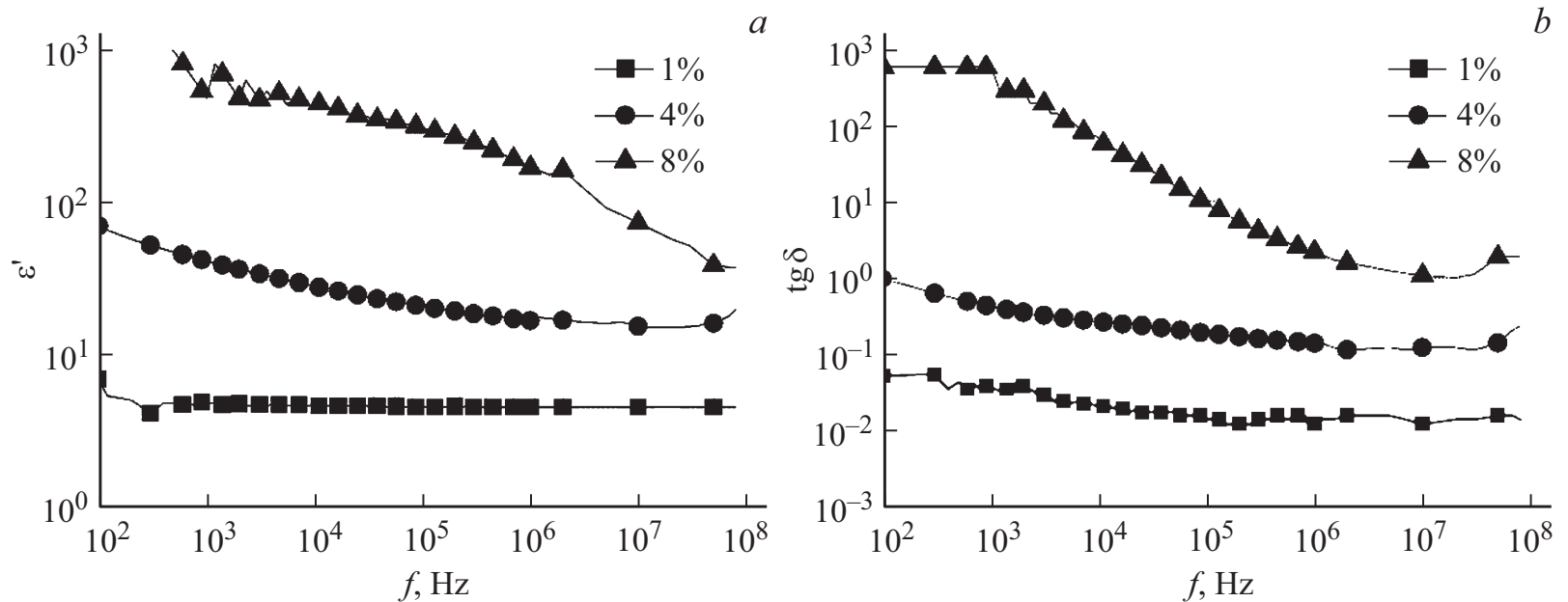

Рис. 1. Зависимости действительной части ДП и тангенса угла диэлектрических потерь композитов от частоты: $a-$ зависимость $\varepsilon^{\prime}(f) ; b-$ зависимость $\operatorname{tg} \delta(f)$.

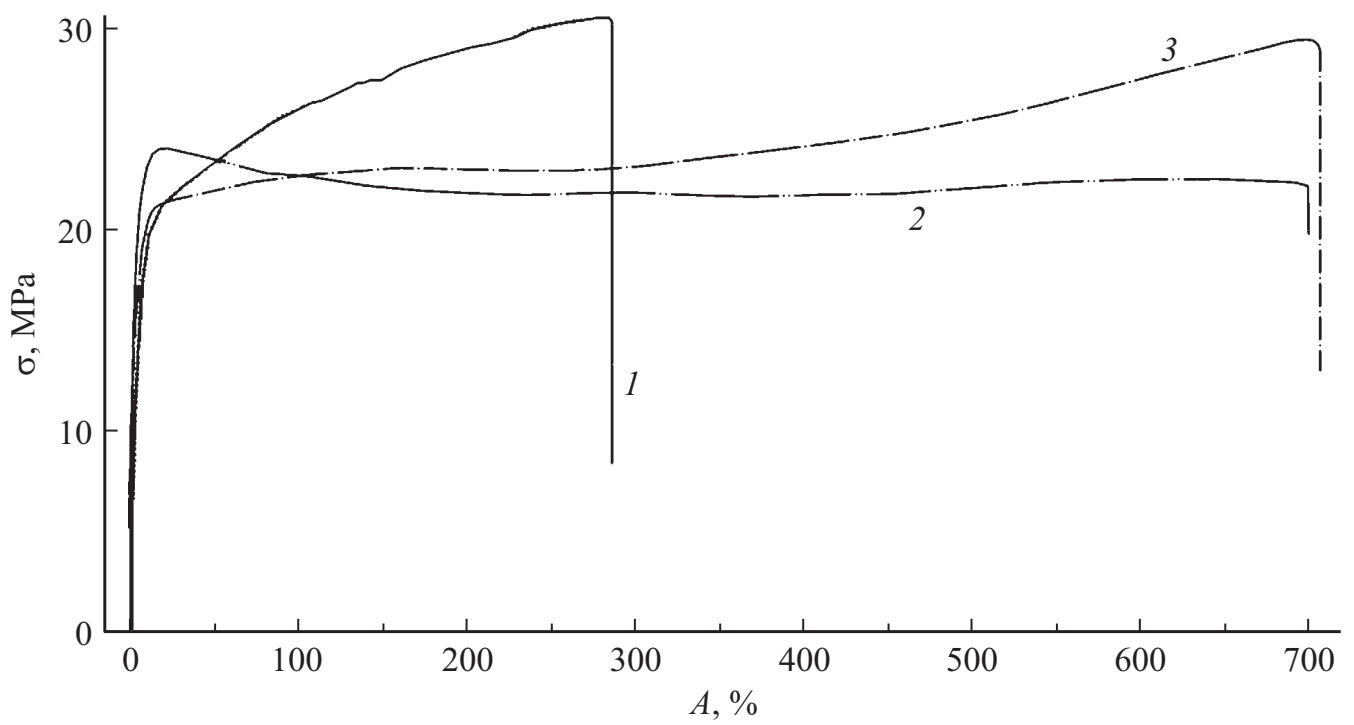

Рис. 2. Кривые зависимостей условного напряжения от относительного удлинения при растяжении исходного СВМПЭ (1), композита СВМПЭ-МУНТ 1\% (2) и материала СВМПЭ-УЗ (3).

Материал, содержащий 1\% МУНТ, имеет повышенную по сравнению с чистым СВМПЭ $(\varepsilon=2.3)$ диэлектрическую проницаемость, равную 4.5, которая практически не зависит от частоты в области от $100 \mathrm{~Hz}$ до $100 \mathrm{MHz}$. При этом величина тангенса угла диэлектрических потерь находится на низком уровне порядка $10^{-2}$ (рис. $1, b)$. Низкочастотная проводимость композита с $1 \%$ МУНТ равна $3 \cdot 10^{-9} \mathrm{Sm} \cdot \mathrm{m}^{-1}$, что указывает на отсутствие в материале сквозной электропроводящей сети контактов, не смотря на высокое содержание нанотрубок. Повышенная ДП и низкие диэлектрические потери в данном композите могут быть объяснены поляризацией однородно распределенных не контактирующих между собой мелких кластеров и индивидуальных МУНТ под действием внешнего электрического поля. Этот материал был выбран для дальнейших исследований механических характеристик и обозначен „СВМПЭ-МУНТ 1\%“.

На рис. 2 представлены кривые, построенные в координатах условного напряжения $\sigma$ от относительного удлинения $A$, полученные при растяжении исходного СВМПЭ, диэлектрического композита, содержащего 1\% МУНТ и образца СВМПЭ-УЗ, полученного после УЗ обработки СВМПЭ в ксилоле без МУНТ.

На рис. 2 видно, что характеристики исследуемых материалов при растяжении существенно различаются. Исходный СВМПЭ характеризуется типичной для такого полиэтилена диаграммой напряжение-деформация с областями упругой деформации и деформационного упрочнения, характеризующегося увеличением напряжения с ростом удлинения. Исходный СВМПЭ имеет предел прочности $30 \mathrm{MPa}$, модуль упругости, равный 


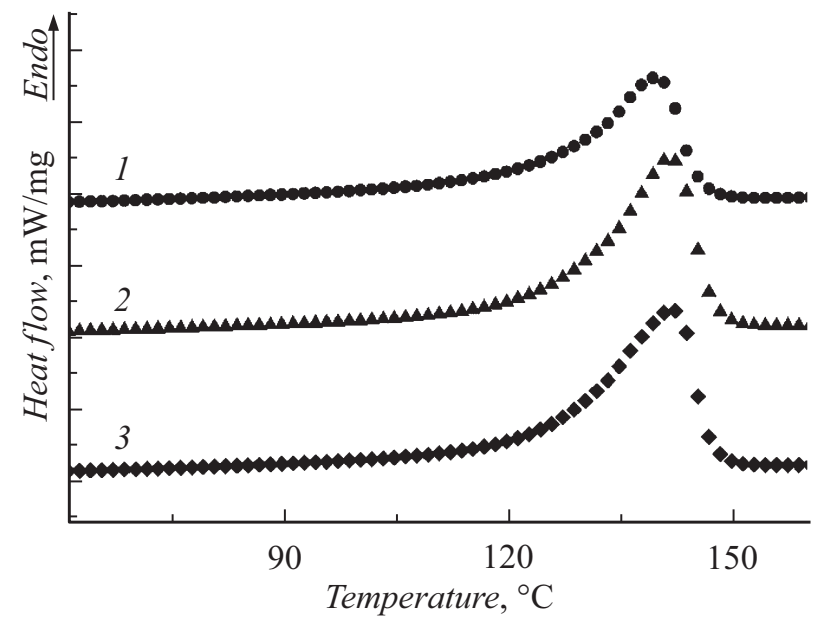

Рис. 4. Кривые ДСК тестов образцов исходного СВМПЭ (1), композита СВМПЭ-МУНТ 1\% (2) и СВМПЭ-УЗ (3).

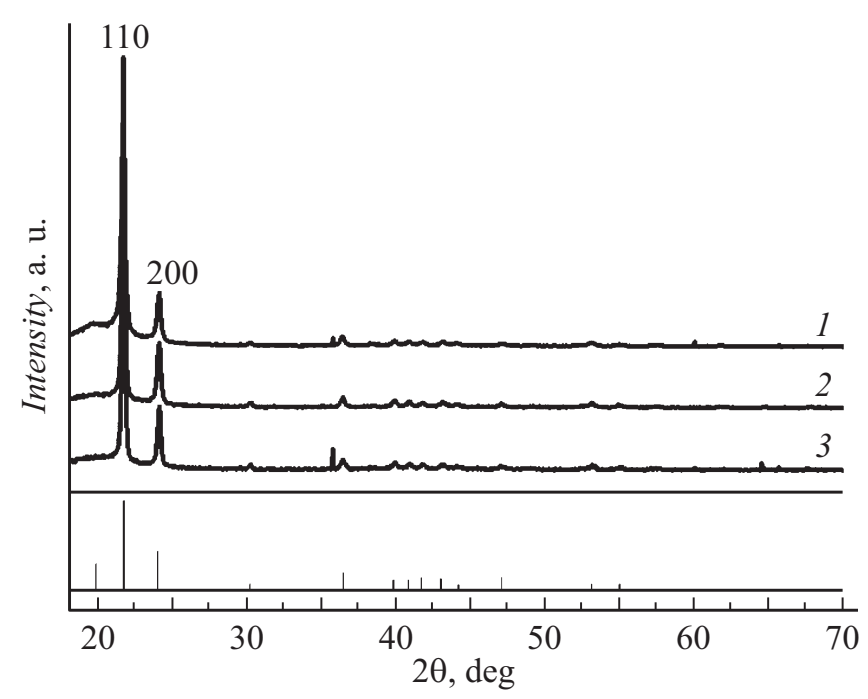

Рис. 5. Дифрактограммы образцов исходного СВМПЭ (1), композита СВМПЭ-МУНТ 1\% (2) и СВМПЭ-УЗ (3).

на $139^{\circ} \mathrm{C}$, а степень кристалличности $46 \%$. Композит СВМПЭ-МУНТ 1\% и образец СВМПЭ-УЗ, имеют повышенную температуру плавления равную $142^{\circ} \mathrm{C}$ и увеличенную кристалличность 56\%.

На рис. 5 представлены дифрактограммы исследуемых материалов, на которых два самых высоких рефлекса (110) и (200) соответствуют орторомбической модификации СВМПЭ матрицы. Методом РФА зафиксировано увеличение степени кристалличности от 70\% для исходного СВМПЭ до $80 \%$ для материалов СВМПЭ-МУНТ 1\% и СВМПЭ-УЗ, а также увеличение областей когерентного рассеяния с $35 \mathrm{~nm}$ для исходного СВМПЭ до $43 \mathrm{~nm}$ для материалов СВМПЭ-МУНТ 1\% и СВМПЭ-УЗ. Обращает на себя внимание большое различие величин степени кристалличности, полученных методами ДСК и РФА, для соответствующих образцов. Однако для устране- ния количественных разногласий определения величины кристалличности, полученных этими двумя методами, требуются дополнительные исследования. В настоящей работе обращаем внимание на то, что методы ДСК и РФА подтверждают увеличение кристалличности образцов СВМПЭ-МУНТ 1\% и СВМПЭ-УЗ на 10\% по сравнению с исходным СВМПЭ.

Согласно результатам исследования методами ДСК и РФА, описанным выше, МУНТ не вносят изменений в структуру СВМПЭ. К аналогичным выводам пришли авторы работы [39], в которой методом РФА изучены композиты на основе полиэтилена с добавкой МУНТ, полученные способом in situ полимеризации. Таким образом, фактором, определяющим механические характеристики композита СВМПЭ-МУНТ 1\%, является не наличие в нем нанотрубок, а УЗ воздействие, используемое в процессе его получения. Судя по всему, УЗ воздействие на раствор СВМПЭ при высокой температуре $130^{\circ} \mathrm{C}$ приводит к нарушению ван-дер-ваальсовых связей между отдельными полимерными цепями, которые распределяются в среде растворителя в виде индивидуальных цепочек или слабосвязанных сгустков. При охлаждении раствора свободные полимерные цепи формируют энергетически выгодные кристаллические фазы с меньшей потенциальной энергией, что было зафиксировано ДСК и РФА методами. При этом увеличивается размер структурных образований, что, судя по всему, приводит к соответствующему увеличению модуля упругости материалов. Можно предположить, что аморфная фаза полимера получается менее „запутанной“, чем у исходного СВМПЭ, что объясняет увеличение пластичности материалов, полученных при $130^{\circ} \mathrm{C}$. Увеличение износостойкости также можно объяснить снижением „переплетения“ полимерных цепей в материале, что уменьшает способность абразивных частиц наждачной бумаги, используемой в тесте на истираемость, вырывать фрагменты образца. В результате поверхность материала после истирающего воздействия приобретает волокнистую текстурированную структуру (рис. $3, b, c$ ), в отличие от изношенной поверхности чистого СВМПЭ (рис. 3,a). Введение МУНТ в СВМПЭ при температуре перемешивания $130^{\circ} \mathrm{C}$ снижает прочность полиэтилена при растяжении (рис. 2). По-видимому, отсутствует надежная связь между СВМПЭ и МУНТ, которые при этом являются дефектами, распределенными в матрице полимера.

\section{Заключение}

Методом перемешивания компонентов в растворе при температуре $130^{\circ} \mathrm{C}$ с использованием ультразвукового воздействия был получен композит на основе СВМПЭ с добавкой 1 wt.\% МУНТ, который обладает повышенной диэлектрической проницаемостью равной 4.5 и низкими диэлектрическими потерями порядка $10^{-2}$, которые практически не зависят от частоты в области измерения 
от $100 \mathrm{~Hz}$ до $100 \mathrm{MHz}$. Композит характеризуется пределом текучести $24 \mathrm{MPa,} \mathrm{прочностью} \mathrm{при} \mathrm{разрыве} 22 \mathrm{MPa}$ и огромным удлинением $700 \%$. Стойкость к истиранию на $37 \%$ выше, чем у чистого СВМПЭ. Показано, что введение МУНТ в СВМПЭ перемешиванием с помощью ультразвукового воздействия при температуре $130^{\circ} \mathrm{C}$ изменяет механические свойства полиэтилена не за счет введения нанотрубок, а за счет УЗ воздействия на раствор полимера, в результате чего при охлаждении формируется отличная от исходной микроструктура полимера с повышенной степенью кристалличности.

\section{Благодарности}

Благодарим Мацько М.А. к.х.н., зав. лаб. Института катализа им. Г.К. Борескова СО РАН и его коллег за помощь в работе.

\section{Конфликт интересов}

Авторы заявляют, что у них нет конфликта интересов.

\section{Список литературы}

[1] Harm Werff, Ulrich Heisserer. // Adv. Fibrous Compos. Materials for Ballistic Protection. Woodhead. Cambridge. 2016. Edition 1. Chapte 3. P. 71-108. DOI: $10.1016 / \mathrm{B} 978-1-78242-461-1.00003$

[2] Roelof Marissen. // Mater. Sci. Applicat. 2011. Vol. 2. N 5. P. 319-330. DOI: $10.4236 / \mathrm{msa} .2011 .25042$

[3] Wei Li, Dangsheng Xiong, Xiaoduo Zhao, Liangliang Sun, Jun Liu. // Mater. Design. 2016. Vol. 102. P. 162-167. DOI: 10.1016/j.matdes.2016.04.006

[4] Karthikeyan K., Russell B.P. // Mater. Design. 2014. Vol. 63. P. 115-125. DOI: 10.1016/j.matdes.2014.05.069

[5] Ansaria F., Gludovatz B., Kozak A., Ritchie R.O., Pruitt L.A. // J. Mechan. Behavior of Biomed. Mater. 2016. Vol. 60. P. 267-279. DOI: 10.1016/j.jmbbm.2016.02.014

[6] Maksimkin A.V., Senatov F.S., Danilov V.D., Mostovaya K.S., Kaloshkin S.D., Gorshenkov M.V., Kharitonov A.P., Chukov D.I. // Mendeleev Commun. 2016. Vol. 26. N 4. P. 350-352. DOI: 10.1016/j.mencom.2016.07.028

[7] Senatov F.S., Kopylov A.N., Anisimova N.Yu., Kiselevsky M.V., Maksimkin A.V. // Mater. Sci. Eng.: C. 2015. Vol. 48. P. 566-571. DOI: 10.1016/j.msec.2014.12.050

[8] Baena J.C., Wu J., Peng Z. // Lubricants. 2015. Vol. 3. N 2. P. 413-436. DOI: 10.3390/lubricants3020413

[9] Plumlee K., Schwartz C.J. // Wear. 2009. Vol. 267. N 5-8. P. $710-717$. DOI: $10.1016 /$ j.wear.2008.11.028

[10] Xiong D.S., Lin J.M., Fan D.L. // Biomed. Mater. 2006. Vol. 1. N 3. P. $175-179$. DOI: $10.1088 / 1748-6041 / 1 / 3 / 013$

[11] Композиционный износостойкий материал на основе сверхвысокомолекулярного полиэтилена (СВМПЭ). Патент РФ. RU 2381242 C2. 2010. Бюл. № 4. / Селютин Г.Е., Гаврилов Ю.Ю., Попова О.Е., Воскресенская Е.Н., Полубояров В.А., Ворошилов В.А., Турушев А.В.

[12] Sebastian M.T., Sherin Thomas, Sumesh George // Appl. Electromagnet. Conf. (AEMC). 2009. P. 1-4. DOI: 10.1109/AEMC.2009.5430628
[13] Kobayashi Y., Tanase T., Tabata T., Miwa T., Konno M. // J. Europ. Ceramic Society. 2008. Vol. 28. N 1. P. 117-122. DOI: 10.1016/j.jeurceramsoc.2007.05.007

[14] Xie Shu-Hui, Zhu Bao-Ku, Wei Xiu-Zhen, Xu Zhi-Kang, $X u$ You-Yi. // Composites: Part A. 2005. Vol. 36. N 8. P. 1152-1157. DOI: 10.1016/j.compositesa.2004.12.010

[15] Maпu K.M., Soni S., Murthy V.R.K., Sebastian M.T. // J. Mater. Sci.: Mater. Electron. 2013. Vol. 24. N 6. P. 2098-2105. DOI: 10.1007/s10854-013-1064-y

[16] Varghese J., Nair D.R., Mohanan P., Sebastian M.T. // Phys. Chem. Chem. Phys. 2015. Vol. 17. P. 14943-14950. DOI: $10.1039 / \mathrm{c} 5 \mathrm{cp} 01242 \mathrm{~b}$

[17] Macutkevic J., Paddubskaya A., Kuzhir P., Banys J., Maksimenko S., Kuznetsov V.L., Mazov I.N., Krasnikov D.V. // J. Nanosci. Nanotechnol. 2014. Vol. 14. N 7. P. $5430-5434$. DOI: doi:10.1166/jnn.2014.8705

[18] Li Q., Xue Q., Zheng Q., Hao L., Gao X. // Mater. Lett. 2008. Vol. 62. N 26. P. 4229-4231. DOI: $10.1016 /$ j.matlet.2008.06.047

[19] Romasanta L.J., Hernández M., López-Manchado M.F., Verdejo R. // Nanoscale Res. Lett. 2011. Vol. 6. P. 1-6. DOI: $10.1186 / 1556-276 \mathrm{X}-6-508$

[20] Meschi Amoli B., Ahmad Ramazani S.A., Hadi Izadi // J. Appl. Polymer Sci. 2012. Vol. 125. P. E453-E461. DOI: 10.1002/app.36368

[21] Ruan S.L., Gao P., Yang X.G., Yu T.X. // Polymer. 2003. Vol. 44. N 19. P. 5643-5654. DOI: $10.1016 / \mathrm{S} 0032-3861(03) 00628-1$

[22] Maksimkin A.V., Kaloshkin S.D., Kaloshkina M.S., Gorshenkov M.V., Tcherdyntsev V.V., Ergin K.S., Shchetinin I.V. // J. Alloys Compounds. 2012. Vol. 536. N 1. P. 538-540. DOI: 10.1016/j.jallcom.2012.01.151

[23] Ma P.-C., Siddiqui N.A., Marom G., Kim J-K. // Compos. Part A. 2010. Vol. 41. N 10. P. 1345-1367. DOI: $10.1016 /$ j.compositesa.2010.07.003

[24] Lisunova M.O., Mamunya Ye.P., Lebovka N.I., Melezhyk A.V. // Europ. Polymer J. 2007. Vol. 43. N 3. P. 949-958. DOI: 10.1016/j.eurpolymj.2006.12.015

[25] Mierczynska A., Mayne-L'Hermite M., Boiteux G., Jeszka J.K. // J. Appl. Polymer Sci. 2007. Vol. 105. N 1. P. 158-168. DOI: 10.1002/app.26044

[26] Pang H., Chen C., Bao Yu, Chen J., Ji Xu, Lei J., Li ZhongMing // Mater. Lett. 2012. Vol. 79. P. 96-99.

DOI: $10.1016 /$ j.matlet.2012.03.111

[27] Bin Y., Yamanaka A., Chen Q., Xi Y., Jlang X., Matsuo M. // Polymer J. 2007. Vol. 39. N 6. P. 598-609. DOI: $10.1295 /$ polymj.PJ2006229

[28] Елеикий А.В., Книжниик А.А., Потапкин Б.В., Кенни Х.В. // УФН. 2015. Т. 185. Вып. 3. С. 225-270. [Eletskii A.V., Knizhnik A.A., Potapkin B.V., Kenny J.M. // Usp. Fizicheskikh Nauk. 2015. Vol. 185. N 3. P. 225-270.] DOI: $10.3367 /$ UFNr.0185.201503a.0225

[29] Deplancke T., Lame O., Barrau S., Ravi K., Dalmas F. // Polymer. 2017. Vol. 111. P. 204-213. DOI: $10.1016 /$ j.polymer.2017.01.040

[30] Maksimkin A.V., Kaloshkin S.D., Kaloshkina M.S., Gorshenkov M.V., Tcherdyntsev V.V., Ergin K.S., Shchetinin I.V. // J. Alloys Compounds. 2012. Vol. 536. P. S538-S540. DOI: 10.1016/j.jallcom.2012.01.151

[31] Maksimkin A.V., Mostovaya K.S., Senatov F.S., Chukov D.I., Nematulloev S.G., Olifirov L.K. // Results in Phys. 2017. Vol. 7. P. 1044-1045. DOI: 10.1016/j.rinp.2017.02.024 
[32] Bakshi S.R., Tercero J.E., Agarwal A. // Composites Part A: Appl. Sci. Manufactur. 2007. Vol. 38. N 12. P. 2493-2499. DOI: 10.1016/j.compositesa.2007.08.004

[33] Maksimkin A.V., Kharitonov A.P., Mostovaya K.S., Kaloshkin S.D., Gorshenkov M.V., Senatov F.S., Chukov D.I., Tcherdyntsev V.V. // Composites Part B: Eng. 2016. Vol. 94. P. 292-298. DOI: 10.1016/j.compositesb.2016.03.061

[34] Balogun Y.A., Buchanan R.C. // Composites Sci. Technol. 2010. Vol. 70. N 6. P. 892-900.

DOI: 10.1016/j.compscitech.2010.01.009

[35] Mazova I., Kuznetsov V.L., Simonova I.A., Stadnichenko A.I., Ishchenko A.V., Romanenko A.I., Tkachev E.N., Anikeeva O.B. // Appl. Surf. Sci. 2012. Vol. 258. N 17. P. 6272-6280. DOI: 10.1016/j.apsusc.2012.03.021

[36] Маркевич И.А., Селютин Г.Е., Дрокин Н.А., Беляев Б.А. // Журнал СФУ. Техника и технологии. 2018. Т. 11. Вып. 2. C. 190-197. [Markevich I.A., Selyutin G.E., Drokin N.A., Belyaev B.A.] // Zh. Sib. Fed. Univ. Tekh. Teknhol. 2018. Vol. 11. N 2. P. 190-197.] DOI: 10.17516/1999-494X-0022

[37] Pradhan D.K., Choudhary R.N.P., Samantaray B.K. // Int. J. Electrochem. Sci. 2008. Vol. 3. P. 597-608.

[38] Bhateja S.K., Yarbrough S.M., Andrews E.H. // J. Macromol. Sci., Part B: Phys. 1990. Vol. 29. N 1. P. 1-10. DOI: $10.1080 / 00222349008212332$

[39] Kazakova M.A., Selyutin A.G., Semikolenova N.V., Ishchenko A.V., Moseenkov S.I., Matsko M.A., Zakharov V.A., Kuznetsova V.L. // Compos. Sci. Technol. 2018. Vol. 167. N 20. P. 148-154. DOI: 10.1016/j.compscitech.2018.07.046 